\title{
COVID-19 and all-cause-mortality; differential trends between countries and selected states of India
}

\author{
Jaideep C. Menon ${ }^{1 *}$, Rakesh P. Suseela ${ }^{2}$, Omesh K. Bharti ${ }^{3}$, Kaushik Mishra ${ }^{4}$, Basanta Swain ${ }^{5}$, \\ Sunil Raina ${ }^{6}$, Denny John ${ }^{2}$, Chandrasekhar Janakiram ${ }^{7}$, Amitava Banerjee ${ }^{2,8}$
}

\begin{abstract}
${ }^{1}$ Preventive Cardiology and Population Health Sciences, ${ }^{2}$ Department of Public Health, ${ }^{7}$ Department of Dentistry and Public Health, Amrita Institute of Medical Sciences, Amrita Vishwa Vidyapeetham, Kochi, Kerala, India

${ }^{3}$ State Epidemiological officer, State Institute of Health and Family Welfare, Government of Himachal Pradesh, India ${ }^{4}$ Superintendent, Head of Community Medicine, Shri Jagannath Medical College and Hospital, Puri, Odisha, India ${ }^{5} \mathrm{Head}$, State Surveillance unit, IDSP, Directorate of Public health, Government of Odisha ${ }^{6}$ Department of Community Medicine, Dr Rajendra Prasad Government Medical College, Tanda

${ }^{8}$ Institute of Health Informatics, University College of London, London, UK and Adjunct Faculty, Department of Public health, Amrita Institute of Medical Sciences, Kerala, India
\end{abstract}

Received: 26 July 2021

Revised: 09 September 2021

Accepted: 06 September 2021

\author{
*Correspondence: \\ Dr. Jaideep C Menon, \\ E-mail: menon7jc@gmail.com
}

Copyright: () the author(s), publisher and licensee Medip Academy. This is an open-access article distributed under the terms of the Creative Commons Attribution Non-Commercial License, which permits unrestricted non-commercial use, distribution, and reproduction in any medium, provided the original work is properly cited.

\begin{abstract}
By 22nd January 2021, the Severe acute respiratory syndrome coronavirus-2 (SARS-CoV-2) virus had infected over 98 million and 10.6 million individuals globally and in India, with 1.7 million and 153, 067 deaths, respectively. Case Fatality rates (CFR) due to coronavirus disease 2019 (COVID 19) have varied significantly between countries. In order to understand the true impact of the pandemic, we should report coronavirus (COVID-19) mortality in the context of all-cause and non-COVID-19 mortality, and compare with previous years. The consequences of the pandemic have been, and will be, different in different settings within and across countries. To compare the all-cause mortality in the year 2020 with previous years in three selected states of India correlate it to the burden of COVID19 and compare allcause mortality between three states of India to four high income countries. We provide quantitative data in three states across India (Himachal Pradesh, Kerala and Odisha) and compare with high-income countries to illustrate the importance of context-specific data monitoring and public health responses. There was a $1.9 \%$ increase in deaths, with $2.8 \%$ decrease in births in 2020, compared to 2019 in Himachal Pradesh, 13.3 and 9.2\% decrease in Kerala and 16.7\% and $21.4 \%$ decrease in Odisha. There was a direct correlation of all cause mortality to CFR on comparison between three states of India and despite the enormous burden of COVID19 in India all-cause mortality was lower compared to previous years in addition to the CFR due to COVID 19 being lower than in selected HICs.
\end{abstract}

Keywords: COVID19, All-cause-mortality, Non-communicable diseases, Case-fatality rate

\section{INTRODUCTION}

\section{All-cause mortality- lessons from current and past pandemics}

Health systems worldwide, including those of developed economies are struggling to prevent spread and mortality due to coronavirus disease 2019 (COVID-19), without neglecting other health and societal priorities. ${ }^{1}$ It is clear that COVID-19 has direct effects through infection, and indirect effects through changes and strains on health systems and behaviours of individuals, whether patients or health professionals. Despite increasing recognition of impact on acute and long-term morbidity, mortality is the 
most frequently used measure of impact and of comparison between countries and over time. All-cause mortality is an important measure of overall health, relevant across a wide spectrum of diseases., 2,3 Through a "syndemic" lens, COVID-19, NCDs (non-communicable diseases) and social determinants of health are interplaying with health system preparedness and political decision-making. Allcause, COVID-19 and non-COVID-19 mortality need to be understood to estimate and mitigate direct and indirect impact, and to inform actions required at system level. ${ }^{4}$ In India, with a higher NCD burden that any other country, this approach is especially important, and comparison with other countries severely affected by the pandemic, may also be informative.

Previous pandemics have been associated with increased all-cause mortality, as well as deaths not directly attributable to the pandemic, especially NCDs and other infections. For example, the Spanish flu pandemic of 19171918, influenza, severe acute respiratory syndrome (SARS) and Middle-Eastern Respiratory Syndrome (MERS) have followed these patterns. During the influenza pandemic globally between 1957 and 1959, excess respiratory mortality rate was $1.9 / 10000$ population (95\% confidence interval 1.2-2.6 cases/10 000 population). ${ }^{5}$ Excess mortality rates varied 70 -fold across countries; Europe and Latin America experienced the lowest and highest rates, respectively.The $\mathrm{H} 1 \mathrm{~N} 1$ pandemic was associated with 11.1 excess all-cause deaths per 100,000 population during the threewaves of virus activity in Mexico, April-December 2009.

The effect of the COVID-19 pandemic on all-cause mortality has been highly variable across countries. In Denmark, timely lockdown measures meant that all-cause mortality for the first six months of 2020 was not increased compared with that of 2015-2019. ${ }^{6}$ In the USA, between March 1 and May 30, 2020, there were 95,235 COVID-19 deaths, and 122,300 excess deaths, leaving $22 \%$ unattributed to COVID-19. ${ }^{7}$ The proportion of excess deaths that were attributed to COVID-19 varied between states and increased over time. In Italy, excess and COVID-19 deaths were 26,701 and 13,710, respectively, showing significant indirect effects of the pandemic. ${ }^{8}$ Across 21 countries, the first wave of the pandemic (from mid-February through the end of May 2020) led to over 200,000 excess deaths. Bulgaria, New Zealand, Slovakia, Australia, Czech Republic, Hungary, Poland, Norway, Denmark and Finland avoided a detectable rise in all-cause mortality, contrasting with the UK, Spain, Italy and Belgium, where the all-cause death toll was very high. ${ }^{9}$

\section{Objectives}

To compare the all-cause mortality in the year 2020 with previous years in three selected states of India correlate it to the burden of COVID19 and compare all-cause mortality between three states of India to four high income countries. We provide quantitative data in three states across India (Himachal Pradesh, Kerala and Odisha) and compare with four high-income countries, namely the US, UK, Spain and Italy.

\section{METHODS}

\section{Study design}

The study was an observational study.

We compared population size, COVID-19 and nonCOVID deaths, crude fatality rate (CFR), prevalence of NCDs (from Global Burden of Disease 2016 data) and proportion of the population $>65$ years of age in India, USA (National Vital Statistics System, NVSS), UK (Office for National Statistics), Spain (Instituto Nacional de Estadistice, INE) and Italy (Worldometer). ${ }^{14}$

Table 1: COVID-19 burden and deaths, all-cause mortality comparison between 2019 and 2020, countries and states.

\begin{tabular}{|c|c|c|c|c|c|c|c|}
\hline \multirow[b]{2}{*}{ State/Country } & \multicolumn{5}{|l|}{ COVID-19 } & \multicolumn{2}{|l|}{ Mortality } \\
\hline & $\begin{array}{l}\text { Cases per } \\
100000 \\
\text { population } \\
\text { (December } \\
\mathbf{3 1 , 2 0 2 0 )}\end{array}$ & $\begin{array}{l}\text { Case } \\
\text { Fatality } \\
\text { Rate }\end{array}$ & $\begin{array}{l}\text { Deaths per } \\
100,000 \\
\text { population }\end{array}$ & $\begin{array}{l}\text { All- } \\
\text { cause } \\
(2019)\end{array}$ & $\begin{array}{l}\text { All- } \\
\text { cause } \\
(\mathbf{2 0 2 0})\end{array}$ & $\begin{array}{l}\text { Annual } \\
\text { crude death } \\
\text { rate per } \\
\mathbf{1 0 0 , 0 0 0} \\
(\mathbf{2 0 1 9 )}\end{array}$ & $\begin{array}{l}\text { Annual crude } \\
\text { death rate per } \\
100,000 \\
(2020)\end{array}$ \\
\hline $\begin{array}{l}\text { Himachal } \\
\text { Pradesh }\end{array}$ & 855 & 1.7 & 13.1 & 43633 & 44480 & 587 & 593 \\
\hline Kerala & 2132 & 0.4 & 8.4 & 263901 & 228739 & 755 & 641 \\
\hline Odisha & 786 & 0.6 & 4.5 & 340595 & 283483 & 732 & 603 \\
\hline USA & 6241 & 1.7 & 106 & $\begin{array}{l}1443000 \\
\wedge\end{array}$ & 1626000 & 872 & 977 \\
\hline $\mathbf{U K}$ & $3911 *$ & $2.8^{*}$ & $111 *$ & $\begin{array}{l}530841 \\
@\end{array}$ & 604045@ & 792 & 962 \\
\hline Italy & 3568 & 3.5 & 125 & $435250^{\wedge}$ & $475674^{\wedge}$ & 1439 & 1571 \\
\hline Spain & 4190 & 2.6 & 110 & $187382^{\wedge}$ & $231014^{\wedge}$ & 802 & 976 \\
\hline
\end{tabular}

$\wedge$ data till June $30^{\text {th }}$, @ data for the first 42 weeks of the year, *51 week data. 
Table 2: Comparing burden of COVID-19, NCD burden, and proportion of the population with an age > 65 years in India and four countries particularly affected by the pandemic.

\begin{tabular}{|llllll|}
\hline & India & USA & UK & Spain & Italy \\
\hline Number of cases & $10,466,595$ & $22,009,275$ & $3,072,353$ & $2,025,560$ & $2,276,491$ \\
\hline Total deaths & 151,160 & 369,304 & 81,431 & 51,690 & 78,755 \\
\hline $\begin{array}{l}\text { Cases per million* } \\
\text { Death per million* }\end{array}$ & 758.4 & 6649.3 & 4525.7 & 4332.3 & 3765.2 \\
\hline $\begin{array}{l}\text { CFR* } \\
\text { NCD burden calculated } \\
\begin{array}{l}\text { as DALYs per year, } \\
\text { million population }\end{array}\end{array}$ & 10.9 & 111.6 & 119.9 & 110.5 & 130.2 \\
\hline $\begin{array}{l}\text { Proportion of } \\
\text { population }>\text { age 65 }\end{array}$ & 1.4 & 1.7 & 2.6 & 2.5 & 3.5 \\
years & $6.4 \%$ & $233,333.3$ & $224,464.8$ & 208620.7 & 227677.1 \\
\hline
\end{tabular}

*as of 12th January $2021 @$ as of 2016, Global burden of diseases
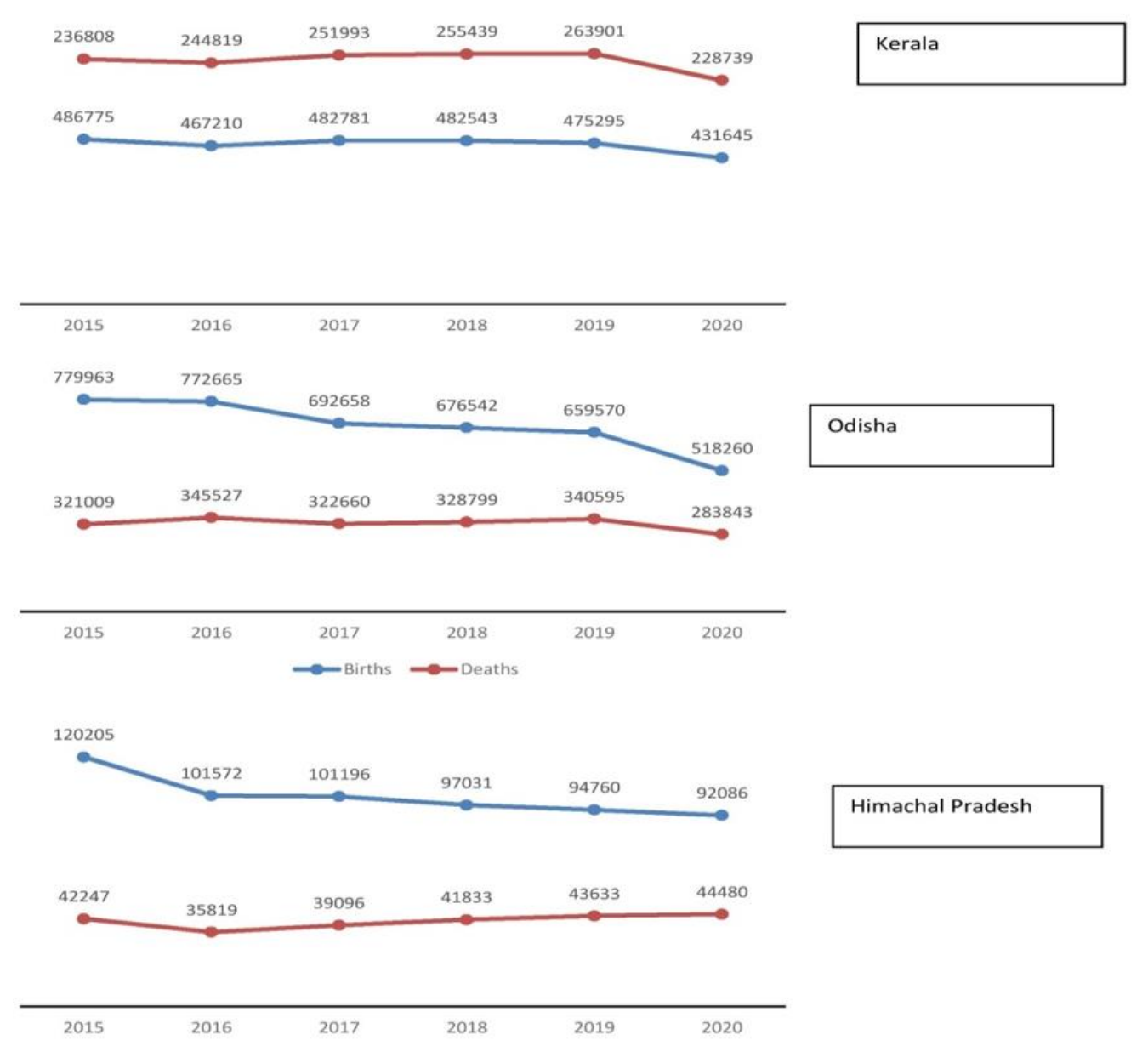

Figure 1: Trend of births and deaths across Himachal Pradesh, Kerala and Odisha.

For the Indian states of Himachal Pradesh, Kerala, and Odisha, birth and death data were collated from Local Self Government websites and State Epidemiology offices of respective states, comparing 2020 with the preceding five years. (Table 1). ${ }^{12,13,17}$

The three Indian states were selected on the basis of data availability.

\section{RESULTS}

In the northern state of Himachal Pradesh, there was a $1.9 \%$ increase in deaths, with $2.8 \%$ decrease in births in 2020, compared to 2019 (Figure 1). In the southern state of Kerala, all-cause mortality and total birth rate reduced by $13.3 \%$ and $9.2 \%$ respectively in 2020 , compared to 2019 . All-cause mortality and births decreased by $16.7 \%$ and 
$21.4 \%$ in the eastern state of Odisha. Himachal Pradesh has a higher CFR $(1.7 \%)$ than Kerala $(0.4 \%)$ and Odisha $(0.6 \%)$.

\section{DISCUSSION}

India, a country of 1.37 billion, has the largest total NCD burden in the world with significant health and social inequities. Given the scale of infection in India, and the increased risk of mortality associated with underlying NCDs, COVID-19 and non-COVID-19 mortality is expected to be high. In India, health and healthcare are organised at the state level within the federal system of the country, with significant differences between states in terms of health-related indices, but mortality has not been investigated in India compared with other countries, or between states in India in the COVID-19 context, to our knowledge. (Table 1)

India has faced lower burden of COVID-19 cases and deaths per million (758 and 11) than other countries (example- USA: 6649 and 112, and UK: 4526 and 120 respectively), resulting in a relatively lower CFR $(1.4 \%)$, compared with USA (1.7\%) and UK (2.6\%). ${ }^{15}$ The proportion of the population aged $>65$ years is lower, and the burden of NCDs per million population per year is also lower, compared with other countries. ${ }^{16}$ (Table 2).

\section{CONCLUSION}

\section{Lessons from India}

Many potential causes have been proposed to explain the low CFR in India, including extensive BCG vaccination coverage, enteric biomes, relatively low population density in rural India and younger population. Official statistics suggest the role of the relatively younger age of the Indian population and the lower prevalence of NCDs, compared with many developed countries worse affected by the pandemic. The decrease in all-cause mortality in Kerala and Odisha has been underlined by significant reductions in emergencies in specialties from paediatrics and cardiology to neurology and orthopaedics, as reported by respective clinical associations and media, although underreporting is possible. Decreases in clinical interventions and surgical procedures, as well as sales of antibiotics have also been reported, which tally with reduced burden of disease.

Reduced all-cause mortality could be related to reductions in deaths due to myocardial infarctions, strokes, road traffic accidents, non-COVID lower respiratory tract infections, and acute exacerbations of chronic respiratory diseases. Other contributing factors may include behavioural changes, such as use of masks, hand washing and sanitisation, decreased alcohol and tobacco consumption due to lack of availability and healthier dietary habits. Moreover, lockdown has led to lower environmental pollution, potentially better care of vulnerable groupsand greater attention to health at individual, community and media level. On the other hand, indirect effects of the pandemic on treatment of acute and chronic non-COVID disease, including cancer, cardiovascular disease and rehabilitation care may lead to morbidity and mortality in coming months and years. There are significant differences in incidence, deaths and CFR due to COVID-19 between populations and countries. Unlike previous pandemics, all-cause mortality has actually been lower or on par with previous years in three states of India, compared with significantly higher mortality rates in many high-income countries. High quality data from all states is required to facilitate further research regarding the low COVID 19 case fatality rate in Kerala and India, as well as breakdown of cause of death and age-specific mortality.

Funding: No funding sources

Conflict of interest: None declared

Ethical approval: Not required

\section{REFERENCES}

1. WHO Coronavirus Disease (COVID-19) Dashboard. Available at: www.covid19.who.int. Accessed on 22 January 2021.

2. Piccininni M, Rohmann JL, Foresti L, Lurani C, Kurth T. Use of all cause mortality to quantify the consequences of covid-19 in Nembro, Lombardy: descriptive study. BMJ. 2020;369:m1835.

3. GBD 2015 Mortality and Causes of Death Collaborators. Global, regional, and national life expectancy, all-cause mortality, and cause-specific mortality for 249 causes of death, 1980-2015: a systematic analysis for the Global Burden of Disease Study 2015. Lancet. 2016;388(10053):1459-544.

4. Horton R, Offline: COVID-19 is not a pandemic. Commentary. Lancet. 2020;396(10255):874

5. ViboudC, Simonsen L, Fuentes R, Flores J, Millar MA, Chowell G. Global mortality impact of the 1957-1959 influenza pandemic. The Journal of Infectious Diseases. 2016;213:738-45.

6. Mills EHA, Møller AL, Gnesin F, Zylyftari N, Broccia M, Jensen B et al. National all-cause mortality during the COVID-19 pandemic: a Danish registry-based study. Eur J Epidemiol. 2020;35(11):1007-19.

7. Weinberger DM, Chen J, Cohen T, Crawford FW, Mostashari F, Olson D et. al. Estimation of excess death associated with the COVID-19 pandemic in the United States, March to May 2020. JAMA Internal Medicine. 2020;180(10):1336-44.

8. Mannucci E, Nreu B, Monami M. Factors associated with increased all-cause mortality during the COVID-19 pandemic in Italy. Int $\mathbf{J}$ Infect Dis. 2020;98:121-4.

9. Kontis V, Bennett JE, Rashid T. Magnitude, demographics and dynamics of the effect of the first wave of the COVID-19 pandemic on all-cause mortality in 21 industrialized countries. Nature Medicine. 2020;26:1919-28. 
10. Roser M, Ritchie R. Burden of Disease. Available at: https://ourworldindata.org/burden-of-disease. Accessed on 21 January 2021.

11. National Vital Statistics System. Available at: https://www.cdc.gov/nchs/nvss/index.htm-. Accessed on 21 January 2021.

12. Office for National Statistics, UK. Available at: https://www.ons.gov.uk/. Accessed on 21 January 2021.

13. Instituto Nacional Estadistica. Available at: https://www.ine.es/en/. Accessed on 21 January 2021.

14. Real time world statistics. Available at: worldometers.info. Accessed on 21 January 2021.

15. European Centre for disease prevention and control. Available at: https://www.ecdc.europa.eu/en/ geographical-distribution-2019-ncov-cases.

Accessed on 21 January 2021.

16. Our World in data. Available at: https://ourworldindata.org/burden-of-disease.Accessed on 21 January 2021.

17. Local self-government- Kerala. Available at: http://lsgkerala.gov.in/en/node/10. Accessed on 21 January 2021.

Cite this article as: Menon JC, Suseela RP, Bharti OK, Mishra K,Swain B, Raina S et al. COVID-19 and all-cause-mortality; differential trends between countries and selected states of India. Int J

Community Med Public Health 2021;8:5040-4. 